\title{
Asistencia de pacientes con fibrosis quística
}

\author{
Tratamiento, detección sistemática y desenlace clínico
}

\section{Birgitta Strandvik}

Departamento de Pediatría, Instituto de Ciencias Clínicas, Academia Sahlgrenska, Universidad de Göteborg,

Göteborg, Suecia

\section{Palabras clave}

Nutrición · Ácidos grasos esenciales · Staphylococcus aureus • Pseudomonas aeruginosa $\cdot$ Tratamiento intravenoso a domicilio · Trasplante $\cdot$ Detección neonatal sistemática • Tasa de supervivencia

\section{Extracto}

La fibrosis quística (FQ), la enfermedad pediátrica hereditaria autosómica más corriente, ha dejado de estar limitada a la infancia desde que la terapia moderna ha proporcionado a los pacientes una mayor longevidad y una mejor calidad de vida. Cuando se identificó el gen, hace más de 16 años, y se descubrió la mutación más corriente, $\Delta \mathrm{F} 508$, se suscitó la esperanza general de una rápida curación de la enfermedad. Aunque el descubrimiento acarreó un considerable impulso de la investigación sobre la fisiopatología, hasta la fecha las mejoras del tratamiento clínico se deben por completo a desarrollos en el contexto del tratamiento tradicional. Las mejorías del estado de los pacientes se vinculan a mejores aportes complementarios de enzimas pancreáticas y a un tratamiento nutricional más intensivo, incluyendo la atención debida al metabolismo anormal de los lípidos. El tratamiento pulmonar ha desembocado en una mejor conservación de la función pulmonar en la edad adulta, con acceso a toda una batería de antibióticos eficientes y al desarrollo de nuevas estrategias: agentes mucolíticos en combinación con el fomento de la actividad física a partir de una edad temprana, conjuntamente con modificaciones en la fisiote- rapia y mejores resultados en los trasplantes pulmonares como último recurso terapéutico. La hepatopatía goza de un mayor reconocimiento y se trata a menudo a largo plazo con ácido ursodesoxicólico, si bien su efecto en la prevención de la progresión de la hepatopatía no ha sido explorado en todos sus extremos. La detección sistemática neonatal se practica cada vez más, afrontando problemas a corto plazo, como los de naturaleza psicológica, cuando se descubren portadores o casos muy leves, y explorando los resultados a largo plazo para demostrar la mejoría del estado clínico y el incremento adicional de la supervivencia. Las limitaciones en la supervivencia, todavía presentes, parecen deberse principalmente al misterio que subyace a la colonización crónica de las vías respiratorias por microorganismos.

Copyright $\odot 2006$ Nestec Ltd., Vevey/S. Karger AG, Basel

\section{Introducción}

Cuando entre 1936 y 1938 se identificó la fibrosis quística (FQ) como entidad independiente de la enfermedad celíaca $[1,2]$, su tratamiento era muy limitado y, en consecuencia, la mortalidad seguía siendo elevada durante los primeros años de vida [3]. Aunque el caso del primer paciente diagnosticado en la edad adulta se describió en 1960 [4], la falta de conocimiento de la enfermedad entre los médicos es todavía muy amplia, de manera que casos leves podrían pasar inadvertidos, posiblemente de por vida. Un problema que destaca en el tratamiento de los

\begin{tabular}{ll}
\hline KARGER & ( 2006 Nestec Ltd., Vevey/S. Karger AG, Basel \\
Fax +41613061234 & \\
$\begin{array}{l}\text { E-Mail karger@karger.ch } \\
\text { www.karger.com }\end{array}$ & $\begin{array}{l}\text { Accesible online en: } \\
\text { www.karger.com/ans }\end{array}$
\end{tabular}


pacientes con FQ es que los casos muy leves pueden deteriorarse también rápidamente después de padecer infecciones víricas o debido a factores no identificados hasta la fecha, lo que implica que, una vez establecido el diagnóstico, el estado de preparación para tratar los síntomas leves es importante. Esta circunstancia ha ratificado la detección sistemática neonatal, si bien no se dispone todavía de medios curativos. Dado que la eficacia de los aportes complementarios precoces de enzimas pancreáticas resultó insatisfactoria y que los problemas nutricionales eran considerables, la mortalidad en la infancia era predominante, y en los gastroenterólogos pediátricos recaía la responsabilidad principal de la asistencia de los pacientes con FQ. Las consecuencias del desarrollo de aportes complementarios de enzimas pancreáticas en microesferas con recubrimiento entérico fueron las siguientes: mejora de la eficacia, mejor absorción de los nutrientes y mejor supervivencia temprana; subsiguientemente, los síntomas pulmonares recibieron mayor atención. En la década de los 70 , numerosos antibióticos $\beta$-lactámicos nuevos posibilitaron abordar mejor el tratamiento pulmonar y, con el desarrollo ulterior del tratamiento de la neuropatía, la atención primaria fue asumida crecientemente por los neumólogos. La mejora de los resultados del trasplante de pulmón cambiará de nuevo el enfoque hacia las complicaciones gastrointestinales, como enfermedades hepáticas y biliares, así como también hacia otros problemas relacionados con la FQ: por ejemplo, complicaciones renales, fragilidad ósea, diabetes y problemas de fertilidad. A su vez, esta situación aclarará la necesidad de centralizar la atención de los pacientes con FQ en un equipo de profesionales, tanto de la asistencia médica como personal sanitario relacionado. A medida que los pacientes viven más tiempo y presentan mejores condiciones para una vida social normal, las estrategias terapéuticas tienen que adaptarse para mejorar el cumplimiento con el tratamiento. Esto enfrenta a los profesionales a nuevos retos en la asistencia de los pacientes con FQ.

\section{Organización de la asistencia para pacientes con FQ}

Ya en la década de los 60 se reconoció que la asistencia centralizada de los pacientes afectados de FQ mejoraba la supervivencia, y que una cooperación estrecha entre los centros dedicados a la FQ y los médicos locales interesados en los problemas de esta enfermedad, podría contribuir también a mejorar la asistencia, siempre y cuando los pacientes fuesen revisados por lo menos una vez al año en el centro [5]. El motivo reside en los matices de los síntomas manifiestos, cuya identificación exige una experiencia considerable por parte del médico en ejercicio para instaurar un tratamiento óptimo. Esto implica también que un centro dedicado a la asistencia de los pacientes con FQ no debe ser demasiado pequeño, es decir, no debe atender a menos de 50 pacientes, y probablemente tampoco demasiado extenso, dado que el conocimiento personal del paciente individual facilita la evaluación correcta del estado real y la posible necesidad de un tratamiento más intensivo. Se ha demostrado que la supervivencia y el estado general de los pacientes mejoran si son revisados una vez al mes en comparación con visitas más espaciadas. También se admite actualmente que un centro debe organizarse como equipo, formado por un médico, una enfermera, un fisioterapeuta, un dietista, un trabajador social, un psicólogo, una secretaria y un auxiliar técnico para realizar las pruebas del sudor [6]. También es necesario contar con instalaciones de expertos, como la cooperación con especialistas en genética, un servicio bacteriológico interesado en los problemas específicos del cultivo de esputos de pacientes con FQ, un servicio de fisiología clínica interesado en evaluaciones pulmonares, un servicio de radiología, etc. Unos pocos centros de FQ deben relacionarse estrechamente con servicios donde se realicen trasplantes pulmonares y hepáticos.

\section{Necesidades dietéticas de energía}

Se recomienda que los pacientes con FQ reciban un aporte de energía del $120 \%$ en comparación con los controles sanos, debido al incremento de su índice metabólico basal [7]. Aunque el gasto total de energía difiere en función de la actividad física y el deterioro de la función pulmonar, existen resultados contradictorios con respecto a una asociación con el genotipo $[8,9]$. Si bien algunos pacientes medran sin el aporte complementario extra de energía [10], la mayoría de los estudios demuestran que, en general, los pacientes con FQ presentan dificultades en cumplir, incluso, con la ingestión de energía recomendada, lo que podría contribuir a problemas en la consecución de un crecimiento normal [11]. En este contexto, merece la pena destacar que pacientes con mutaciones, como $\Delta$ F508, cuya asociación con una elevada necesidad de energía se ha dado a entender, también presentan insuficiencia pancreática y parecen más propensos a desarrollar una deficiencia de ácidos grasos esenciales [12]. En ratas, la deficiencia de ácidos grasos esenciales se asocia a un incremento del gasto de energía. 
Para obtener una elevada ingestión de energía, estos pacientes precisan una dieta rica en energía, es decir, una dieta que contribuya con un 40 a $45 \%$ de la energía (\%E) en comparación con el máximo del $30 \% \mathrm{E}$ en adultos sanos; sin embargo, sólo unos pocos pacientes ingieren tal cantidad de grasa [11]. No obstante, es indispensable corregir los bien documentados niveles plasmáticos bajos de ácido linoleico (18:2n-6). En consecuencia, los ácidos grasos poliinsaturados deben contribuir al 10-15\%E. Una ingestión elevada de ácidos grasos n- 6 normaliza habitualmente los bajos niveles séricos de ácido docosahexaenoico $[12,13]$. Los pacientes con FQ se benefician de una mayor ingestión de ácidos grasos n-3, dado que los eicosanoides del ácido eicosapentaenoico (20:5n-3), la prostaglandina $\mathrm{E}_{3}$ y la serie de leucotrienos-5 son antiinflamatorios y pueden contrarrestar el incremento de la producción de eicosanoides a partir de la cascada del ácido araquidónico (20:4n-6), elevado en la FQ [14, 15], la mayoría de los cuales estimulan la inflamación.

El aumento de la actividad física, como parte del tratamiento moderno, incrementa la necesidad de energía. Las exacerbaciones pulmonares, con un aumento de la frecuencia respiratoria, y el impacto general de la infección elevan adicionalmente la necesidad de energía extra, sobre todo en pacientes gravemente enfermos. Al mismo tiempo, el incremento de las citocinas, causado por la infección, puede deteriorar el apetito, lo que suele hacer que las comidas constituyan un problema para los pacientes afectados de FQ [16]. Este problema requiere ingenio en la estimulación del comer con objeto de evitar un desplazamiento al metabolismo catabólico, que puede convertirse rápidamente en un proceso que exija la aplicación de medidas invasivas, como la nutrición enteral.

El empleo de aportes complementarios comercialmente disponibles, en forma de refrigerios, puede incrementar la ingestión de energía, pero no son beneficiosos si se utilizan para reducir las comidas normales, dado que su contenido en hidratos de carbono es análogamente elevado, y los ácidos grasos de cadena media (grasa de triglicéridos de cadena media) no son sustitutos del ácido linoleico. En niños pequeños, las exacerbaciones de las infecciones de las vías respiratorias pueden deteriorar transitoriamente la función pancreática residual, y la diarrea o las molestias digestivas pueden constituir un síntoma precoz indicativo de la necesidad de un tratamiento más agresivo, tanto de la insuficiencia pancreática como de la infección pulmonar.

Incluso con el tratamiento complementario pancreático actualmente disponible, tanto en condiciones estables como durante las exacerbaciones, muy a menudo es bas-

Detección, terapia y resultados clínicos en FQ tante difícil normalizar la absorción de las grasas, lo que indica la necesidad de mejorar ulteriormente este tratamiento, así como la participación de otros factores en el deterioro de la absorción de las grasas [17]. En ensayos clínicos se están estudiando nuevos aportes complementarios pancreáticos, procedentes de lipasas bacterianas y lipasa recombinante estimulada por sales biliares humanas $[18,19]$. Dado que la insuficiencia hepática grave es infrecuente, una síntesis baja de ácidos biliares como factor contributivo significativo del deterioro de la lipólisis es menos probable [20]. No obstante, las complicaciones biliares pueden reducir el flujo biliar y, en consecuencia, contribuir a concentraciones bajas de sales biliares intraluminales y malabsorción [21]. Otro factor importante podría consistir en que una concentración plasmática baja de ácido linoleico, indicativa de una deficiencia de ácidos grasos esenciales, deteriorase la absorción de grasas por disminución del transporte transcelular de grasa [22]. Debido a la absorción defectuosa en la deficiencia de ácidos grasos esenciales, es decir, las concentraciones bajas de ácido linoleico, podría ser incluso necesario administrar ácido linoleico por vía intravenosa durante una deficiencia grave [23]. Los pacientes con mutaciones relacionadas con un fenotipo grave son más propensos a presentar niveles plasmáticos bajos de ácido linoleico y podrían precisar con mayor regularidad el aporte complementario [12]. Desde un punto de vista práctico, podría recomendarse el empleo del acceso intravenoso durante el tratamiento antibiótico de las exacerbaciones pulmonares en el curso de los tres últimos días del ciclo, y administrar $10 \mathrm{ml}$ de Intralipid al 10\% (o la cantidad correspondiente de emulsiones comparables) $/ \mathrm{kg}$ de peso corporal, diariamente durante 6 a 8 h. Es importante no proceder a la infusión con demasiada rapidez o durante infecciones agudas, dado que la actividad de la lipoproteinlipasa puede estar menoscabada. En este contexto, es preferible la utilización de dispositivos especiales para la infusión de emulsiones. En pacientes con deficiencia grave de ácidos grasos esenciales puede recomendarse un tratamiento similar durante tres días, cada dos a tres semanas en el curso de 4 a 6 meses, para normalizar los niveles séricos de ácido linoleico y obtener una mejoría concomitante de las funciones renal y hepática [24, 25].

En pacientes que ya presenten malnutrición, habitualmente en relación con una función pulmonar gravemente deteriorada, podría ser necesario administrar nutrición enteral (por sonda nasogástrica o a través de gastroenterostomía) para normalizar la antropometría [26]. Las fórmulas para nutrición enteral ricas en energía $(1 \mathrm{kcal} / \mathrm{ml})$ pueden administrarse preferiblemente du-

Ann Nestlé [Esp] 2006;64:131-141 
Tabla 1. Ingestión diaria recomendada de nutrientes en pacientes con $\mathrm{FQ}^{1}$

\begin{tabular}{|c|c|c|}
\hline Energía & $120 \%$ de IDR $^{2}$ & $\begin{array}{l}\text { Algunos pacientes con mutaciones leves no precisan } \\
\text { básicamente de energía extra. Todos los pacientes } \\
\text { necesitan energía extra durante las infecciones. }\end{array}$ \\
\hline \multicolumn{3}{|l|}{ Macronutrientes } \\
\hline Proteína & $15 \% \mathrm{E}$ & \\
\hline Hidratos de carbono & 40 a $45 \% \mathrm{E}$ & $<10 \%$ E en forma de sacarosa \\
\hline \multicolumn{3}{|l|}{ Micronutrientes } \\
\hline \multicolumn{3}{|l|}{ Vitaminas liposolubles } \\
\hline A Retinol & 2.000 a $4.000 \mathrm{UI}(0,45 \mathrm{a} 1,2 \mathrm{mg})$ & Preferentemente, dispersiones acuosas \\
\hline Vitaminas B & & $\begin{array}{l}\text { Habitualmente todas son aportadas con la } \\
\text { alimentación }\end{array}$ \\
\hline Vitamina $\mathrm{B}_{6}$ & 40 a 80 mg/día & $\mathrm{B}_{6}$ puede estar indicada \\
\hline Vitamina C & 30 a 60 mg/día & $\begin{array}{l}\text { La ingestión es a menudo satisfactoria si se acata la } \\
\text { ingestión de frutas recomendada }\end{array}$ \\
\hline \multicolumn{3}{|r|}{ 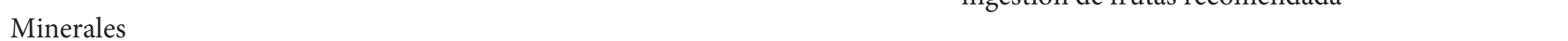 } \\
\hline Cinc & En función de la elección de los alimentos & Es aportado habitualmente en la alimentación \\
\hline Calcio & O igual que la población sana de la misma edad & Ver información adicional en las ref. 28, 29 \\
\hline
\end{tabular}

rante la noche, de manera que no interfieran demasiado con la ingestión de alimentos normales y la vida corriente. El aporte complementario de enzimas antes de acostarse y al comienzo de la infusión suele bastar para obtener una absorción satisfactoria. Este es a menudo un tratamiento necesario en pacientes que permanecen a la espera de un trasplante, pero podría ser incluso más eficiente si se administrase precozmente para problemas de alimentación, en cuyo caso el procedimiento puede ser transitorio. La nutrición parenteral total no está habitualmente indicada.

\section{Aporte complementario de vitaminas}

La dificultad para normalizar la absorción de grasas precisa del aporte complementario extra de vitaminas liposolubles. Dado que los pacientes con FQ presentan un incremento de la capacidad oxidativa cuyo trasfondo se desconoce [27], debe prestarse atención especial a los an- tioxidantes como la vitamina $\mathrm{E}$ y el $\beta$-caroteno, cuyas concentraciones suelen ser muy bajas en la FQ. Aunque la vitamina A es importante para la integridad de la mucosa, debe prestársele una atención especial después de los trasplantes, cuando sus niveles séricos suelen llegar a ser elevados. Las concentraciones séricas de las vitaminas liposolubles tienen que ser monitorizadas periódicamente, por lo menos anualmente, sobre todo si se albergan temores de que los niveles elevados pudieran ser tóxicos. A título de revisión, se remite a los informes de consenso recientes en los que se resumen las prácticas nutricionales $[28,29]$. En la tabla 1 se compendia la recomendación para el tratamiento nutricional.

\section{Tratamiento de las complicaciones intestinales}

En ocasiones, el apetito deficiente guarda relación con un dolor abdominal recurrente, debido a complicaciones intestinales como estenosis o síndrome de obstrucción 
intestinal distal. Aunque la primera de estas complicaciones tiene que ser tratada quirúrgicamente, la segunda puede, en general, aliviarse satisfactoriamente por medio de la aplicación de un enema que contenga $\mathrm{N}$-acetilcisteína al $10 \%$ y solución de contraste radiológico hiperosmolar en una relación 1:1 o 2:1; la cantidad de $N$-acetilcisteína no debe sobrepasar los $300 \mathrm{mg} / \mathrm{kg}$ de peso corporal. En pacientes con recurrencias frecuentes de los síntomas, puede obtenerse cierta ayuda con la ingestión oral de grandes cantidades diarias de polímeros inertes, como una mezcla de tamaños diferentes de polietilenglicol, conjuntamente con ajustes alimentarios que eviten las comidas ricas en fibras [30].

\section{Tratamiento de la neumopatía}

El tratamiento de los síntomas de las vías respiratorias ha suscitado una atención máxima, dado que la neumopatía es responsable del 95\% de la mortalidad en la FQ. Aunque todas las estrategias se basan en una combinación de agentes mucolíticos, actividades físicas pasivas o activas y antibióticos, el éxito varía considerablemente tanto de un país a otro como de un centro a otro [31]. Aunque la mayor atención se ha prestado a la colonización crónica con Pseudomonas aeruginosa, la mayor o menor colonización crónica con Staphylococcus aureus, que precede habitualmente a la anterior, causa una explosión respiratoria muy superior y, por lo tanto, es también más agresiva para los tejidos [32]. Existe un riesgo general de que el temor de la colonización con Pseudomonas, que exige la administración intravenosa de antibióticos, ocasione una negligencia inconsciente con respecto al tratamiento de $S$. aureus. Las especies de $P$. aeruginosa son bacterias aerobias facultativas, muy difundidas en la naturaleza, y los pacientes tratados agresivamente por síntomas leves pueden albergarlas durante décadas sin deterioro de la función pulmonar [33]. Otras bacterias corrientes en la FQ son Haemophilus influenzae y Stenotrophomonas maltophilia. El complejo Burkholderia cepacia es un grupo de bacterias, algunas de cuyas cepas están relacionadas con un curso grave y contagioso, a menudo denominado 'síndrome de cepacia'.

Los tratamientos antibióticos intensivos, a largo plazo, que se aplican en numerosos centros, han ocasionado problemas de cepas resistentes. El temor a la distribución de estas cepas entre los pacientes ha resultado en la separación de unidades de pacientes basada en la colonización bacteriana, lo que causa un estrés psicológico considerable a los pacientes $[34,35]$. En un reciente informe Co- chrane se pregunta si está justificada una evaluación de la elevada carga antibiótica, para mantener la identificación intermitente de $P$. aeruginosa en lugar de la identificación crónica, a las luces de los problemas de las cepas resistentes y la segregación de los pacientes [36]. En una reciente encuesta sobre la política terapéutica en los países nórdicos se ha demostrado que hay centros en los que no se sigue esta política y que presentan una prevalencia comparativamente superior de Pseudomonas entre sus pacientes, aunque un problema menor en lo referente a las cepas resistentes [37]. Estos pacientes gozan de una antropometría y una función pulmonar favorables y, en consecuencia, también de una buena calidad de vida, lo que indica que estrategias terapéuticas alternativas podrían merecer consideración [Lindblad A. y cols, para el Consorcio Escandinavo de FQ; en prensa] (fig. 1).

En la tabla 2 se recopilan diferentes agentes de uso corriente en el tratamiento de la neumopatía. Se han elaborado diversas estrategias terapéuticas, centradas la mayoría en prevenir la colonización crónica con bacterias gramnegativas, principalmente $P$. aeruginosa. Las estrategias se basan en agentes mucolíticos pulmonares generalizados, fisioterapia y antibióticos. El moco muy pegajoso se adhiere a la mucosa y, como sustrato, contribuye a la colonización bacteriana (fig. 2). En el momento del diagnóstico, y para prevenir esta evolución, la mayoría de los centros inicia el tratamiento con agentes mucolíticos solos hasta que se demuestre el aislamiento de bacterias. Este tratamiento puede implicar actividad física [38], así como incluir, desde una edad temprana, fisioterapia sobre bolas y trampolines. En algunos países predomina todavía una fisioterapia más pasiva con palmoteo, basada en la ayuda diaria de fisioterapeutas. A partir del diagnóstico, el empleo de bromhexina por vía oral previene los tapones causados por la acumulación del moco pegajoso y disminuye los síntomas de sinusitis crónica. La inhalación diaria de solución salina fisiológica, broncolíticos y mucolíticos también se instaura precozmente; la frecuencia viene determinada habitualmente por los síntomas. Aunque se ha demostrado que todos los fármacos aumentan la expectoración y mejoran la función pulmonar en pacientes con síntomas pulmonares, su papel como profilácticos es menos evidente. Desde un punto de vista clínico, la selección del fármaco debe ser individualizada, es decir, algunos pacientes consiguen los mejores efectos con dornasa- $\alpha$ y otros, un efecto igualmente favorable aplicando únicamente solución salina $[39,40]$. Con respecto a toda terapéutica inhalatoria, una combinación de actividad física y/o fisioterapia, individualizada también para la adherencia, proporciona 


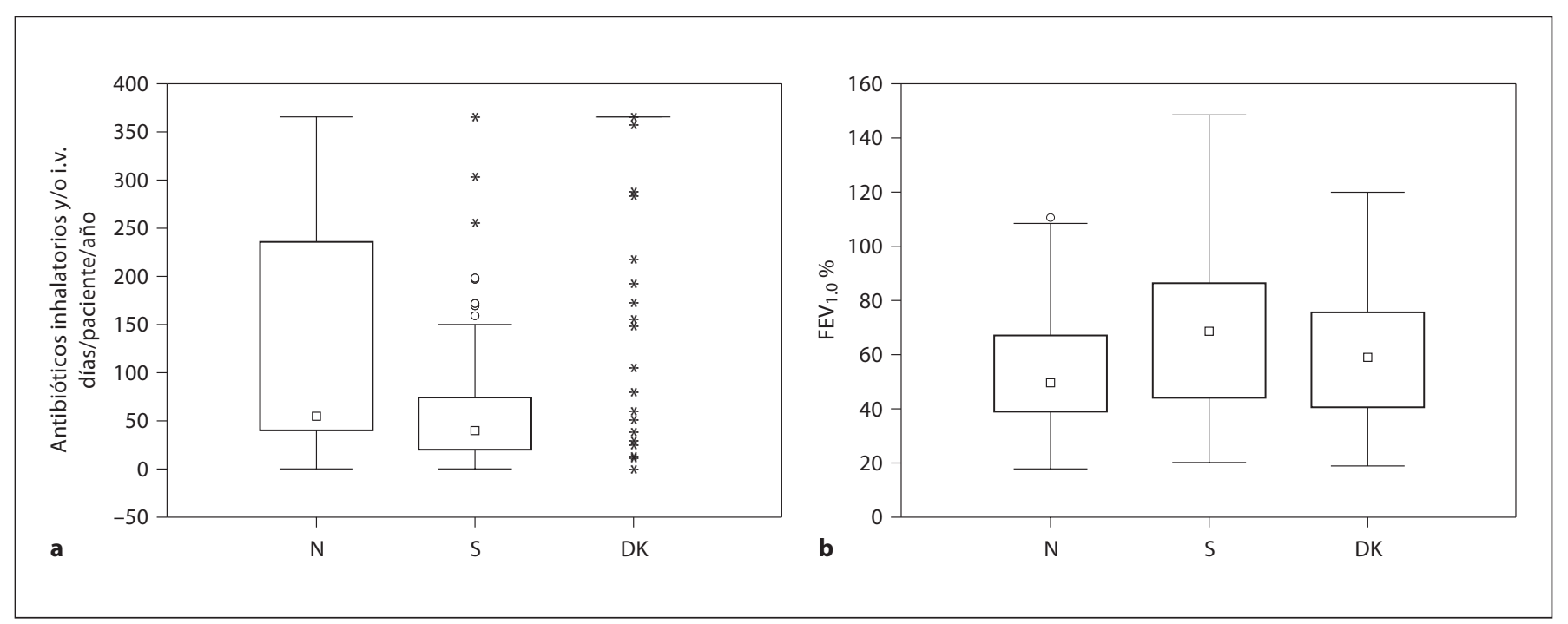

Fig. 1. El diagrama de casillas del tratamiento antipseudomonas en pacientes mayores de 19 años, colonizados crónicamente con P. aeruginosa, en los tres países nórdicos, Noruega (N), Suecia (S) y Dinamarca (DK) (a), y la función pulmonar correspondiente expresada en volumen espiratorio forzado en $1 \mathrm{~s}\left(\mathrm{VEF}_{1.0}\right)$ como porcentaje de los valores previstos (b). a Número de días con antibióticos por vía inhalatoria y/o intravenosa por paciente y año. Se indican las medianas y los percentiles 25 y 75. Las patillas indican los percentiles 5 y 95 ; los puntos, los valores aislados y los asteriscos indican los extremos. Publicado con autorización del Consorcio Escandinavo de FQ, Dr. A. Lindblad.

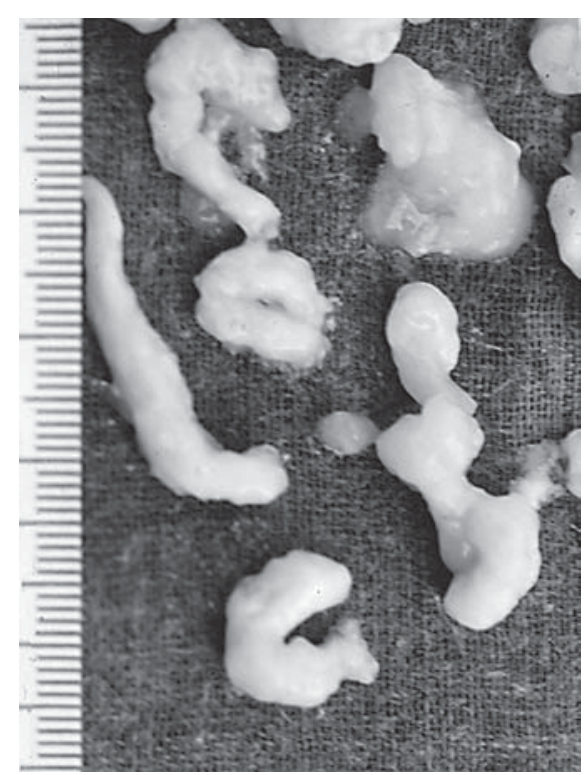

Fig. 2. Tapones de moco obtenidos por broncoscopia en un niño con fibrosis quística. Fotografía: Dr. Jean Feigelson, París, con autorización. el mejor resultado en relación con la expectoración de moco. En los últimos años se ha utilizado azitromicina como mucolítico. Su efecto en pacientes colonizados crónicamente con $P$. aeruginosa es notable, aunque las bacterias no son sensibles al fármaco. La administración a largo plazo ha sido capaz de reducir el número de ciclos antibióticos intravenosos.

\section{Estrategias antibióticas}

En general, S. aureus es tratado cuando se aísla, y el efecto del tratamiento puede monitorizarse fácilmente a través de anticuerpos séricos específicos, como los dirigidos frente al ácido teicoico y la toxina- $\alpha$ [41]. Dado que podría ser difícil obtener muestras de esputo en niños pequeños, en algunos centros se administra tratamiento profiláctico a largo plazo durante la primera infancia con ácido fusídico o flucloxacilina, mientras que otros se abstienen por el temor de poder acelerar la colonización con bacterias gramnegativas. Podría ser importante destacar que la resistencia a la flucloxacilina es extremadamente rara y que en países como Suecia, donde se utiliza este fármaco para el tratamiento a largo plazo, el aislamiento de cepas resistentes a meticilina es todavía infrecuente [37]. 
Tabla 2. Estrategias terapéuticas pulmonares de uso más corriente para mucolíticos y antibióticos ${ }^{1}$

\begin{tabular}{|c|c|c|}
\hline Sustancia & Dosificación & Observaciones \\
\hline \multicolumn{3}{|l|}{ Mucolíticos } \\
\hline \multirow{2}{*}{$\begin{array}{l}\text { Clorhidrato de } \\
\text { bromhexina }\end{array}$} & \multirow[t]{2}{*}{$1 \mathrm{mg} / \mathrm{kg} \mathrm{PC} / 24 \mathrm{~h}$} & Dosis baja, ausencia de efecto por vía oral \\
\hline & & $\begin{array}{l}\text { Puede utilizarse también para inhalación y por vía intravenosa } \\
\text { antes de la fisioterapia }\end{array}$ \\
\hline \multirow[t]{2}{*}{ N-Acetilcisteína } & \multirow[t]{2}{*}{200 a 400 mg 2 veces/día } & Vía oral; actúa principalmente como sustrato para el glutatión. \\
\hline & & $\begin{array}{l}\text { En inhalación, } 200 \text { a } 400 \text { mg preferiblemente en } 2 \text { a } 4 \text { ml de solu- } \\
\text { ción salina } 2 \text { a } 3 \text { veces/día. Puede utilizarse por vía intravenosa } \\
\text { antes de la fisioterapia }\end{array}$ \\
\hline $\begin{array}{l}\text { 2-Mercaptoetano sódico } \\
\text { sulfonato }\end{array}$ & 200 a 400 mg 2 veces/día & Para inhalación en 2 a 4 ml de solución salina \\
\hline $\begin{array}{l}\text { Desoxirribonucleasa } \\
\text { recombinante }\end{array}$ & $2,5 \mathrm{mg}$ & Para inhalación 1 o 2 veces al día (dornasa- $\alpha) 1 \mathrm{mg} / \mathrm{ml}$ \\
\hline Solución salina & 0,45 a $3 \%$ & $\begin{array}{l}\text { Para inhalación, } 2 \text { a } 3 \text { veces/día. Solución hipotónica para tienda } \\
\text { de nebulización, por la noche }\end{array}$ \\
\hline Azitromicina & 250 a $500 \mathrm{mg} 3$ veces por semana & $\begin{array}{l}\text { Sobrecarga durante } 3 \text { días al comienzo; tratamiento a largo plazo } \\
\text { en pacientes colonizados crónicamente con } P \text {. aeruginosa }\end{array}$ \\
\hline \multicolumn{3}{|l|}{ Antibióticos } \\
\hline Flucloxacilina & $100 \mathrm{mg} / \mathrm{kg} \mathrm{PC} / 24 \mathrm{~h}$ & Tratamiento a largo plazo frente a $S$. aureus, sin resistencia \\
\hline Ácido fusídico & $50 \mathrm{mg} / \mathrm{kg} \mathrm{PC} / 24 \mathrm{~h}$ & $\begin{array}{l}\text { Debe administrarse frente a } S \text {. aureus conjuntamente con otros } \\
\text { antibióticos para prevenir resistencias }\end{array}$ \\
\hline Amoxicilina & $50 \mathrm{mg} / \mathrm{kg} \mathrm{PC} / 24 \mathrm{~h}$ & $\begin{array}{l}\text { Primera elección para } H \text {. influenzae. Otras alternativas en fun- } \\
\text { ción de la resistencia }\end{array}$ \\
\hline $\begin{array}{l}\text { Trimetoprim/ } \\
\text { sulfametoxazol }\end{array}$ & 8 a $12+40$ a $60 \mathrm{mg} / \mathrm{kg} \mathrm{PC} / 24 \mathrm{~h}$ & $\begin{array}{l}\text { Alternativa para } H \text {. influenzae, aunque de uso también frecuente } \\
\text { para Stenotrofomonas maltofilia }\end{array}$ \\
\hline Tobramicina & $\begin{array}{l}10 \text { a } 20 \mathrm{mg} / \mathrm{kg} \mathrm{PC} / 24 \text { h i.v. o } \\
\text { inhalación } 300 \mathrm{mg} 2 \text { veces/día }\end{array}$ & $\begin{array}{l}\text { Menos tóxica que otros aminoglicósidos corrientes; uso conjunto } \\
\text { con un } \beta \text {-lactámico para } P \text {. aeruginosa. Para inhalación TOBI }{ }^{\circledR} \text {, } \\
\text { reduce el riesgo de ototoxicidad y nefrotoxicidad }\end{array}$ \\
\hline Amikacina & $15 \mathrm{mg} / \mathrm{kg} \mathrm{PC} / 24 \mathrm{~h}$ & $\begin{array}{l}\text { No es de primera elección; la resistencia incluye siempre resisten } \\
\text { cia a la tobramicina }\end{array}$ \\
\hline Colistina & 2 a $3 \times 10^{6}$ unidades $/ 24 \mathrm{~h}$ & $\begin{array}{l}\text { Aunque se usa habitualmente por vía inhalatoria, puede adminis } \\
\text { trarse también i.v. }\end{array}$ \\
\hline Ceftacidima & $\begin{array}{l}150 \text { a } 250 \mathrm{mg} / \mathrm{kg} \mathrm{PC} / 24 \text { h, } \\
\text { máx. } 3 \text { g } 3 \text { veces i.v. }\end{array}$ & $\begin{array}{l}\text { Frecuente primera elección para } P \text {. aeruginosa; igual que otros } \\
\beta \text {-lactámicos, administrar conjuntamente con tobramicina }\end{array}$ \\
\hline Meronem & $\begin{array}{l}120 \mathrm{mg} / \mathrm{kg} \text { PC/ } 24 \text { h i.v., } \\
\text { máx. } 2 \text { g } 3 \text { veces }\end{array}$ & \\
\hline Cefepim & 150 mg/kg PC/24 h i.v. & \\
\hline Aztreonam & $\begin{array}{l}150 \text { a } 250 \mathrm{mg} / \mathrm{kg} \mathrm{PC} / 24 \mathrm{~h}, \\
\text { máx. } 2,5 \mathrm{~g} 3 \text { veces i.v. }\end{array}$ & \\
\hline Piperacilina & $\begin{array}{l}350 \text { a } 450 \mathrm{mg} / \mathrm{kg} \mathrm{PC} / 24 \mathrm{~h} \text {, } \\
\text { máx. } 4 \text { g } 3 \text { veces i.v }\end{array}$ & $\begin{array}{l}\text { Reacciones alérgicas más corrientes que con otros } \beta \text {-lactámicos. } \\
\text { El efecto mejora en combinación con un inhibidor de } \beta \text {-lactámi- } \\
\text { cos }\left(\text { Tazocin }{ }^{\circledR}\right)\end{array}$ \\
\hline Ciprofloxacilina & $\begin{array}{l}40 \mathrm{mg} / \mathrm{kg} \mathrm{PC} / 24 \mathrm{~h} \text {, } \\
\text { máx. } 1,5 \mathrm{~g} 3 \text { veces }\end{array}$ & Por vía intravenosa 2 o 3 veces/día; por vía oral 2 veces/día \\
\hline
\end{tabular}

\footnotetext{
${ }^{1}$ El uso combinado es corriente y cada centro desarrolla su propia estrategia.
}

En el primer aislamiento de $P$. aeruginosa, el tratamiento agresivo es actualmente la regla y así, la colonización crónica puede quedar pospuesta. La mayoría de los centros utiliza antibióticos intravenosos en forma de una combinación de un aminoglicósido, habitualmente to- bramicina, y un $\beta$-lactámico, seguido de la inhalación de tobramicina o colistina durante semanas a meses [42]. En algunos centros se realizan inhalaciones regulares de tobramicina $\left(\mathrm{TOBI}^{\circledR}\right)$, según un programa de cuatro semanas de tratamiento y cuatro semanas de pausa. Otros uti- 
lizan un esquema similar para la inhalación de colistina. Cuanto más intensivo sea el tratamiento y a más largo plazo se utilice, tanto menor será el riesgo de colonización crónica (definida como más de un aislamiento de P. aeruginosa durante seis meses y títulos de anticuerpos antipseudomonas positivos [43]) y, en cambio, se logra una colonización intermitente a expensas de un elevado consumo de antibióticos. Esta carga intensiva de antibióticos resulta también en una colonización crónica con otros tipos de bacterias, como Achromobacter xylosoxidans. Tal como se ilustra en la figura 1, en el país nórdico con la carga antibiótica más reducida, la función pulmonar de los pacientes era igual de favorable que en los demás países, lo que indica que la estrategia de cómo usar los antibióticos tiene una gran importancia. En algunos pacientes gravemente enfermos, con cepas de Pseudomonas de baja sensibilidad, la infusión continua de $\beta$-lactámicos produce efectos favorables. En general, el riesgo de desarrollo de resistencia es menor si los tratamientos se mantienen durante 7 a 14 días (media: 10 días); cuando se precisan tratamientos más prolongados, deben cambiarse los antibióticos $[33,37]$. En nuestra experiencia, el problema es menor librándose de las cepas mucoides que de las no mucoides. Aunque el motivo no es evidente, podría estar relacionado con la estrategia de utilización de mucolíticos y antibióticos.

El tratamiento antibiótico con fármacos antimicrobianos intravenosos para los signos de exacerbación de los síntomas pulmonares ha sido la modalidad terapéutica más profusamente utilizada. En el esfuerzo para mantener la carga infecciosa en el menor nivel posible, en los últimos años ha sido más corriente el tratamiento inhalatorio más o menos continuo. El desarrollo de un preparado especial de tobramicina para el tratamiento inhalatorio $\left(\mathrm{TOBI}^{\circledR}\right)$ ha cambiado la política terapéutica en numerosos países, desde la administración intravenosa hasta un programa de administración de antibióticos a largo plazo, durante cuatro semanas con pausas de cuatro semanas, demostrándose que mejora y mantiene la función pulmonar de manera más bien constante durante periodos de tiempo prolongados [44]. Pueden obtenerse resultados similares con el tratamiento tradicional, utilizando una combinación de tobramicina y $\beta$-lactámico, con menos problemas en relación con la resistencia antimicrobiana de las cepas bacterianas $[33,45]$. Esto se ilustra por el hecho de que en el país nórdico con el menor consumo de antibióticos para pacientes con FQ en raras ocasiones se utiliza terapéutica inhalatoria. Los costes del tratamiento intravenoso pueden mantenerse también a un nivel relativamente bajo enseñando a los padres y a los pacientes cómo practicar el tratamiento antibiótico intravenoso a domicilio, lo cual también concede más libertad a la familia y, en consecuencia, un mayor cumplimiento con el tratamiento y una mayor aceptación del mismo [46]. También la obtención de muestras de sangre, que es indispensable durante cada ciclo, después de la tercera dosis del aminoglicósido, para controlar la dosificación e introducir ajustes para evitar la toxicidad, puede realizarse a domicilio y entregar las muestras en el hospital.

En ocasiones se plantea un problema cuando aparece una reacción alérgica al fármaco antimicrobiano preferido, o incluso al único al cual la bacteria es sensible en las pruebas in vitro. Este incidente puede superarse con una desensibilización muy cuidadosa, comenzando con concentraciones muy bajas del antibiótico durante el ciclo actual [47]. Pueden ser necesarios periodos de tratamiento más prolongados, especialmente en pacientes gravemente enfermos a la espera de trasplantes pulmonares, y la variación de los antibióticos adquiere entonces importancia.

\section{Administración o no de esteroides}

Aunque a veces se utilizan esteroides para reducir la inflamación, su administración sistémica aumenta el riesgo de diabetes clínica y, en consecuencia, deben utilizarse con limitaciones. El empleo de nuevas formulaciones de esteroides para inhalación se ha incrementado, si bien no se dispone todavía de investigaciones demostrativas de si el efecto antiinflamatorio de los esteroides es más eficaz que el tratamiento antibiótico [48].

\section{Tratamiento de la hipoxemia}

La oximetría periférica debe verificarse con regularidad, dado que una oxigenación baja puede aparecer insidiosamente, incluso cuando la función pulmonar parece estar bien conservada. Los mecanismos que subyacen al respecto no son evidentes. El primer signo suele aparecer por la noche durante exacerbaciones pulmonares [49] y, aunque se trata de un fenómeno perfectamente identificado, no se dispone de investigaciones en la FQ demostrativas de cuál debe ser el mejor tratamiento [50]. Aunque a menudo se recomienda a pacientes con deterioro moderado de la oxigenación un aporte complementario nocturno, en cierto nivel, el suministro continuo de oxígeno es necesario. A la espera del trasplante, el tratamiento de ventilación con apoyo de presión puede ser útil y un complemento necesario para exacerbaciones graves [51]. La respiración asistida con una máquina está contraindicada, dado que puede ser imposible destetar el paciente del la intubación. 


\section{Indicación para el trasplante de pulmón}

Los pacientes deben ser considerados para trasplante cuando su función pulmonar se deteriora en presencia de un $\mathrm{VEF}_{1.0}<30 \%$ de los valores previstos. La decisión de incluir al paciente en la lista de espera para trasplantes de pulmón debe tomar en consideración numerosos factores, como nutrición, tasa de declinación de la función pulmonar, tipo de colonización bacteriana, factores psicológicos, etc. [52].

\section{Detección sistemática}

La detección sistemática de la FQ fue introducida por primera vez en los años 60 , utilizando la determinación de albúmina fecal como indicador de insuficiencia pancreática. Nunca ha sido utilizada profusamente debido a problemas importantes derivados de los resultados falsos positivos y falsos negativos. Se comprobó que el incremento de la tripsina inmunorreactiva en el suero tenía mayor especificidad y sensibilidad, y recientemente ha sido utilizado como primer instrumento, en ocasiones repetido y sometido habitualmente a seguimiento por análisis de mutaciones en las mutaciones de presentación regional más corrientes antes de la realización de la prueba del sudor [53]. La finalidad de instaurar la detección sistemática estriba en prevenir la aparición de daños pulmonares, y si bien los resultados a corto plazo han sido positivos tanto con respecto a la nutrición como a la neumopatía [54], después de los 10 años de edad la mayoría de los estudios muestra una diferencia muy escasa con respecto a los pacientes no sometidos a la detección [55]. Esta constatación ha sido desalentadora, y el informe de consenso más reciente no recomienda todavía en general la detección sistemática para poblaciones generales, pero la considera justificada para regiones y propósitos especiales [53]. Numerosos seguimientos muy cuidadosos de poblaciones sometidas a detección sistemática han incrementado nuestro conocimiento sobre la evolución natural de las manifestaciones iniciales de la enfermedad. Los problemas que derivan de la detección sistemática son los siguientes: diagnóstico de casos asintomáticos o con síntomas iniciales muy leves; diagnósticos de portadores; trastornos precoces del vínculo madre-lactante; incapacidad para identificar síntomas leves en pacientes que han pasado inadvertidos a la detección; y finalmente los costos elevados [55]. Dado que no existe todavía tratamiento curativo de la FQ, la introducción de la detección sistemática debe considerarse regionalmente, en estrecha cooperación con los centros de FQ, y sopesando los costes frente a los beneficios tanto para el individuo como para la sociedad.

\section{Desenlace}

La FQ ya no es una enfermedad limitada a la pediatría. En un número de centros cada vez mayor, la mitad o casi la mitad de los pacientes son adultos. La mediana de la tasa de supervivencia se ha incrementado como mínimo hasta la mitad de la tercera década, tanto en EE.UU. como en Europa Occidental, y en algunos centros es incluso muy superior [56]. No obstante, existen considerables diferencias regionales en el resto del mundo, debido en su mayoría a factores socioeconómicos; por ejemplo, en algunos países de la antigua Europa del este, la ausencia de los tratamientos médicos más básicos no deja opciones para el tratamiento. En el mundo desarrollado, la mayoría de pacientes disfruta actualmente de una vida social satisfactoria, trabajando a tiempo total o a tiempo parcial, y también los hombres con FQ pueden formar una familia debido a la exitosa aspiración de espermatozoides seguida de fertilización in vitro. Aunque la incidencia de diabetes relacionada con FQ aumenta con la edad, este tipo de diabetes puede ser fácil de tratar, y su identificación precoz y el tratamiento con insulina de reacción corta puede prevenir el deterioro que se describe frecuentemente con esta complicación. La hepatopatía nunca influye prácticamente sobre la supervivencia del paciente. Ante todo, no parece progresar en general con la edad y, en caso contrario, el resultado del trasplante hepático es actualmente satisfactorio en general, a menudo también con mejoría de los síntomas pulmonares [57]. En consecuencia, los trasplantes combinados de pulmón e hígado están raramente indicados, si bien, recientemente, los trasplantes combinados de páncreas e hígado han dado resultados satisfactorios [58]. La longevidad mejora adicionalmente por los resultados favorables del trasplante de pulmón. En general, los pacientes con FQ presentan una mejor supervivencia a 5 años que los pacientes trasplantados por otras enfermedades, probablemente debido a que son más jóvenes y, especialmente, si presentan también un buen estado nutricional $[59,60]$.

\section{Conclusión}

Han trascurrido ya más de 16 años desde que se descubrió el trastorno genético que subyace a esta enfermedad y, basándose en este hecho, se ha obtenido un incre- 
mento notable del conocimiento a partir del aumento considerable de la investigación básica. Aunque hemos asistido al advenimiento de varias innovaciones potenciales para ampliar el tratamiento básico de la enfermedad, hasta la fecha, la enorme mejora de la supervivencia se debe al desarrollo continuo del tratamiento tradicional, la atención centralizada y la constatación de que revisiones frecuentes del paciente pueden llegar a identificar síntomas pulmonares leves. El tratamiento agresivo evitará la aparición de daños pulmonares progresivos. En este contexto, se precisa una observación especial, de manera que el tratamiento a largo plazo con inhalación de antibióticos y las visitas más infrecuentes a la clínica no contrarresten la intención del tratamiento. Es una tarea difícil para el centro y para el equipo motivar a los políticos para que concedan recursos destinados a tratamientos y opciones correctas para salvaguardar el mejor interés del paciente.

\section{Bibliografía}

1 Fanconi G, Uehlinger E, Knauer C: Das Coeliakiesyndrom bei angeborenen zystischer Pancreasfibromatose und Bronchiektasien. Wien Med Wochenschr 1936;86:753-756.

2 Andersen DH: Cystic fibrosis of the pancreas and its relation to celiac disease: a clinical and pathological study. Am J Dis Child 1938; 56:344-399.

3 Bodian M: Fibrocystic Disease of the Pancreas: A Congenital Disorder of Mucus Production - Mucosis. New York, Grune \& Stratton, 1953.

4 Marks BL, Anderson CM: Fibrocystic disease of the pancreas in a man aged 46 . Lancet 1960;1:365.

5 van Koolwijk LME, Uiterwaal CSPM, van der Laag J, et al: Treatment of children with cystic fibrosis: central, local or both? Acta Paediatr 2002;91:972-977.

6 Littlewood JM: Good care for people with cystic fibrosis. Paediatr Respir Rev 2000;1: 179-189.

7 Thomson MA, Wilmott RW, Wainwright C, et al: Resting energy expenditure, pulmonary inflammation, and genotype in the early course of cystic fibrosis. J Pediatr 1996; 129:367-373.

8 O’Rawe A, McIntosh I, Dodge JA, et al: Increased energy expenditure in cystic fibrosis is associated with specific mutations. Clin Sci 1992;82:71-76.

-9 Fried MD, Durie PR, Tsui L-C, et al: The cystic fibrosis gene and resting energy expenditure. J Pediatr 1991;119:913-916.

10 Kindstedt-Arfwidson K, Strandvik B: Food intake in patients with cystic fibrosis on an ordinary diet. Scand J Gastroenterol 1988; 23:160-162.

11 Kawchak DA, Zhao H, Scanlin TF, et al: Longitudinal, prospective analysis of dietary intake in children with cystic fibrosis. J Pediatr 1996;129:119-129.

12 Strandvik B, Gronowitz E, Enlund F, et al: Essential fatty acid deficiency in relation to genotype in patients with cystic fibrosis. J Pediatr 2001;139:650-655.
13 Farrell PM, Mischler EH, Engle MJ, et al: Fatty acid abnormalities in cystic fibrosis. Pediatr Res 1985;19:104-109.

14 Kurlandsky LE, Bennink MR, Webb PM, et al: The absorption and effect of dietary supplementation with omega-3 fatty acids on serum leukotriene $B_{4}$ in patients with cystic fibrosis. Pediatr Pulmonol 1994;18:211-217.

15 Strandvik B, Svensson E, Seyberth HW: Prostanoid biosynthesis in patients with cystic fibrosis. Prostagland Leukotr Essent Fatty Acids 1996;55:419-425.

16 Stark LJ: Can nutrition counselling be more behavioural? Lessons learned from dietary management of cystic fibrosis. Proc Nutr Soc 2003;62:793-799.

17 Baker SS, Borowitz D, Duffy L, et al: Pancreatic enzyme therapy and clinical outcomes in patients with cystic fibrosis. J Pediatr 2005;146:189-193.

18 Strandvik B, Hansson L, Hernell O, et al: Recombinant human bile salt-stimulated lipase improves lipid uptake and reduces the pancreatic enzyme supplementation in patients with cystic fibrosis. Pediatr Pulmonol 2004(suppl 27):333.

19 Borowitz D, Goss CH, Stevens C, et al: Safety and preliminary clinical activity of a novel pancreatic enzyme preparation in pancreatic insufficient cystic fibrosis patients. Pancreas 2006;32:258-263.

20 Strandvik B, Einarsson K, Lindblad A, Angelin B: Bile acid kinetics and biliary lipid composition in cystic fibrosis. J Hepatol 1996;25: 43-48.

21 Harries JT, Muller DPR, McCollum JPK, et al: Intestinal bile salts in cystic fibrosis. Arch Dis Child 1979;54:19-24.

22 Perin N, Jarocka-Cyrta E, Keelan M, et al: Dietary lipid composition modifies intestinal morphology and nutrient transport in young rats. J Pediatr Gastroenterol Nutr 1999;28:46-53.

23 Maqbool A, Schall J, Zemel B, et al: Essential fatty acid deficiency and the relevance of the triene:tetraene ratio in children with cystic fibrosis. J Pediatr Gastroenterol Nutr 2005; 41:550.
24 Strandvik B, Berg U, Kallner A, Kusoffsky E: Effect on renal function of essential fatty acid supplementation in cystic fibrosis. J Pediatr 1989;115:242-250.

25 Strandvik B, Hultcrantz R: Liver function and morphology during long term fatty acid supplementation in cystic fibrosis. Liver 1994;14:32-36.

26 van Biervliet S, De Waele K, van Winckel M, Robberecht E: Percutaneous endoscopic gastrostomy in cystic fibrosis: patient acceptance and effect of overnight tube feeding on nutritional status. Acta Gastroenterol Belg 2004;67:241-244.

27 Brown RK, Kelly FJ: Evidence for increased oxidative damage in patients with cystic fibrosis. Pediatr Res 1994;36:487-493.

28 Sinaasappel M, Stern M, Littlewood J, et al: Nutrition in patients with cystic fibrosis: a European Consensus. J Cyst Fibr 2002;1:5175.

29 Borowitz D, Baker RD, Stallings V: Consensus report on nutrition for pediatric patients with cystic fibrosis. J Pediatr Gastroenterol Nutr 2002;35:246-259.

30 Proesmans M, De Boeck K: Evaluation of dietary fiber intake in Belgian children with cystic fibrosis: Is there a link with gastrointestinal complaints? J Pediatr Gastroenterol Nutr 2002;35:610-614.

31 Ferkol T, Rosenfeld M, Milla CE: Cystic fibrosis pulmonary exacerbations. J Pediatr 2006;148:259-264.

-32 Hollsing AE, Lantz B, Bergström K, et al: Granulocyte elastase-alpha1-antiproteinase complex in cystic fibrosis: sensitive plasma assay for monitoring pulmonary infections. J Pediatr 1987;111:206-211.

33 Strandvik B: Antibiotic therapy of pulmonary infections in cystic fibrosis. Dosage and dose schedules. Chest 1988;94:146S-149S.

34 Koch C, Frederiksen B, Hoiby N: Patient cohorting and infection control. Semin Respir Crit Care Med 2003;24:703-716. 
35 Steinkamp G, Ullrich G: Different opinions of physicians on the importance of measures to prevent acquisition of Pseudomonas aeruginosa from the environment. J Cyst Fibros 2003;2:199-205.

36 Wood DM, Smyth AR: Antibiotic strategies for eradicating Pseudomonas aeruginosa in people with cystic fibrosis. The Cochrane Database of Systematic Reviews 2006; DOI: 10.1002/14651858.CD004197.pub2.

37 Strandvik B, Hjelte L, Malmborg AS: Cystic fibrosis pulmonary infection: the Swedish experience; in Bauernfeind A, Marks MI, Strandvik B (eds): Cystic Fibrosis Pulmonary Infections: Lessons from Around the World. Basel, Birkhäuser, 1996, pp 293-302.

38 Blomquist M, Freyschuss U, Wiman LG, Strandvik B: Physical activity and self treatment in cystic fibrosis. Arch Dis Child 1986; 61:362-367.

39 Suri R: The use of human deoxyribonuclease (rhDNase) in the management of cystic fibrosis. BioDrugs 2005;19:135-144.

40 Elkins MR, Robinson M, Rose BR, et al: A controlled trial of long-term inhaled hypertonic saline in patients with cystic fibrosis. $\mathrm{N}$ Engl J Med 2006;354:229-240.

41 Hollsing AE, Granström M, Strandvik B: Prospective study of serum staphyloccocal antibodies in cystic fibrosis. Arch Dis Child 1987;62:905-911.

42 Cantón R, Cobos N, de Gracia J, et al; on behalf of the Spanish Consensus Group for Antimicrobial Therapy in the Cystic Fibrosis Patient: Antimicrobial therapy for pulmonary pathogenic colonisation and infection by Pseudomonas aeruginosa in cystic fibrosis patients. Clin Microbiol Infect 2005;11:690-703.
43 Ericsson-Hollsing A, Granström M, Vasil M, et al: Prospective study of serum antibodies to Pseudomonas aeruginosa exoproteins in cystic fibrosis. J Clin Microbiol 1987;25: 1868-1874.

44 Cheer SM, Waugh J, Noble S: Inhaled tobramycin (TOBI): a review of its use in the management of Pseudomonas aeruginosa infections in patients with cystic fibrosis. Drugs 2003;63:2501-2520.

45 Blumer JL, Saiman L, Konstan MW, Melnick D: The efficacy and safety of meropenem and tobramycin vs ceftazidime and tobramycin in the treatment of acute pulmonary exacerbations in patients with cystic fibrosis Chest 2005;128:2336-2346.

46 Strandvik B, Hjelte L, Malmborg AS, Widén B: Home intravenous antibiotic treatment of patients with cystic fibrosis. Acta Paediatr Scand 1992;81:340-344.

47 Parmar JS, Nasser S: Antibiotic allergy in cystic fibrosis. Thorax 2005;60:517-520.

48 Dezateux C, Walters S, Balfour-Lynn I: Inhaled corticosteroids for cystic fibrosis. The Cochrane Database Systematic Reviews 2000;2:CD001915.

49 Villa MP, Pagani J, Lucidi V, et al: Nocturnal oximetry in infants with cystic fibrosis. Arch Dis Child 2001;84:50-54.

50 Mallory GB, Fullmer JJ, Vaughan DJ: Oxygen therapy for cystic fibrosis. The Cochrane Database of Systematic Reviews 2005;4. DOI: 10.002/14651858. CD003884.pub2.

51 Dobbin CJ, Milross MA, Piper AJ, et al: Sequential use of oxygen and bi-level ventilation for respiratory failure in cystic fibrosis. J Cyst Fibros 2004;3:237-242.
Rosenbluth DB, Wilson K, Ferkol T, Schuster DP: Lung function decline in cystic fibrosis patients and timing for lung transplantation referral. Chest 2004;126:412-419

53 Grosse SD, Boyle CA, Botkin JR, et al: CDC: Newborn screening for cystic fibrosis: evalutation of benefits and risks and recommendations for state newborn screening programs. MMWR Recomm Rep 2004;53:136.

54 Dankert-Roelse JE, Mérelle ME: Review of outcomes of neonatal screening for cystic fibrosis versus non-screening in Europe. J Pediatr 2005;147:S15-S20.

55 Castellani C: Evidence for newborn screening for cystic fibrosis. Paediatr Respir Rev 2003;4:278-284.

56 Lannefors L, Lindgren A: Demographic transition of the Swedish cystic fibrosis community - results of modern care. Respir Med 2002;96:681-685.

57 Meyburg J, Hoffmann GF: Liver transplantation for inborn errors of metabolism Transplantation 2005;80:S135-S137.

58 Fridell JA, Vianna R, Kwo PY, et al: Simultaneous liver and pancreas transplantation in patients with cystic fibrosis. Transplant Proc 2005;37:3567-3569.

59 Bech B, Pressler T, Iversen M, et al: Longterm outcome of lung transplantation for cystic fibrosis - Danish results. Eur J Cardiol Thorac Surg 2004;26:1180-1186.

60 Ganesh JS, Rogers CA, Bonser RS, Banner NR: Outcome of heart-lung and bilateral sequential lung transplantation for cystic fibrosis: a UK national study. Eur Respir J 2005;25:964-969. 